\title{
TRATAMIENTO DE SEMILLAS DE ALGODON CON Pseudomonas spp. FLUORESCENTES EN EL BIOCONTROL DE Rhizoctonia solani.
}

\author{
(Cotton seed treatment with fluorescent Pseudomonas spp. in \\ Rhizoctonia solani biocontrol)
}

\author{
D.E.G.T. Andrade, S.J. Michereff \& R.L.R. Mariano \\ Área de Fitossanidade, Departamento de Agronomia \\ Universidade Federal Rural de Pernambuco \\ 52171-900 Recife, PE, Brasil \\ E-mail: sami@nelore.npde.ufrpe.br.
}

Palabras clave: Biocontrol, Rhizoctonia solani, algodón, Pseudomonas spp. fluorescentes Key words: Biocontrol, Rhizoctonia solani, cotton, fluorescent Pseudomonas spp.

\section{RESUMEN}

Fue evaluado el efecto del tratamiento de semillas de algodón con Pseudomonas spp. fluorescentes para el control de Rhizoctonia solani. Primeramente se seleccionaron 67 cepas de Pseudomonas para inocular semillas de algodón de lavariedad Precoce-1. Las semillas fueron sumergidas en suspensiones bacterianas ( $10^{5}$ células $\left./ \mathrm{ml}\right)$ preparadas en solución de $\mathrm{M} / \mathrm{gSO}$, $0.1 \mathrm{M}$ y posteriormente sembradas en bandejas con suelo sin esterilizar $e$ infectado con el patógeno (cepa RS-4), en densidad de 50 $\mathrm{mg}$ de sustrato(arroz) colonizado/ $\mathrm{kg}$ de suelo.

La evaluación de la intensidad de la enfermedad se realizó a los 10 dias después de la siembra, utilizandose una escala de valores de 0 a 4 , donde $0=$ sin sintomas y4 = máximo de sintomas.

Los cepas de Pseudomonas $P-8, C R-27, C B-38$, $C B-33$ y $P-5$, fueron más eficaces en el control de los cepas de $\boldsymbol{R}$. solani ( $R S-4, R S-5$ y $R S-6)$, con densidades de inóculos de 50,100 y $150 \mathrm{mg} / \mathrm{kg}$ de suelo. La cepa $C B-33$ ejerció mayor biocontrol que la cepa RS-t del fitopatógeno, así como las cepas CB-38 y CR-27, controlaron las cepas RS-5 y RS-6 respectivamente.

Las cepas bacterianas presentaron mayores niveles de control que el fungicida Quintozene en todas las condiciones.

\section{SUMMARY}

The effect of cotton seed treatment with fluorescent Pseudomonas spp. isolates was evaluated for Rhizoctonia solani control. In a preliminary screening 67 isolates were tested. Cotton seeds, cv. Precoce-1, were immersed in to the bacterial suspensions $\left(10^{5} \mathrm{cells} / \mathrm{ml}\right)$, prepared in $0,1 \mathrm{MMgSO}$, solution and then sown in trays containing non-sterilized soil previously infected with the pathogen (RS-4 isolate), at a density of $50 \mathrm{mg}$ of substrate (colonized rice) $/ \mathrm{kg}$ of soil. The evaluation of disease intensity was carried out after 10 days, using a grade scale from 0 to $+10=$ without symptoms and $4=$ maximum of symptoms).

The Pseudomonas isolates $P-8, C R-27, C B-38, C B$ 33 and $P-5$, showed best disease control and were evaluated in relation to several $R$. solani isolates $(R S-4$, $R S-5$, and RS-6) and inoculum densities (50, 100 and 150 $\mathrm{mg} / \mathrm{kg}$ of soil) under greenhouse conditions: There was large variation in performance of Pseudomonas spp. isolates on $\boldsymbol{R}$. solani control in all experiments. The isolate $C B-33$ was the best biocontrol agent in relation to $R S-4$, while $C B-38$ and $C R-27$ showed the best performance in relation to $R S-5$ and $R S-5$, respectively. The bacterial isolates showed better efficiency than Quintozene treatment in all trials. 


\section{INTRODUCCION}

El cultivo del algodón (Gossypium hirsutum L.) es afectado por diversos hongos geofilicos, sobresaliendo Rhizoctonia solani Kühn, como uno de los patógenos radiculares más comunes e importantes (Cia, 1977), al ocasionar pérdidas debido a las pudriciones de semillas o de cancros en el hipocótilo, culminando con el la caída de plántulas (Watkins, 1981). El control de $R$. solani es extremadamente difícil, porque el uso de variedades resistentes, la rotación de cultivos y el tratamiento de semillas o suelos con fungicidas, muchas veces no son eficaces, debido principalmente a la variabilidad genética que presenta el patógeno, así como a la capacidad de sobrevivencia que posee en el suelo y semillas, pudiendo infectar diferentes cultivos (Leach \& Garber, 1970).

El control biológico de las enfermedades constituye una alternativa viable en aquellos casos en que el tratamiento químico es antieconómico, o cuando las plantas hospedadoras no poseen resistencia genética al patógeno. Además, el biocontrol minimiza los efectos nocivos que ocasionan los productos quimicos, como la contaminación ambiental y el desequilibrio ecológico (Cook \& Baker, 1983). La aplicación de microorganismos antagónicos, a través de semillas y/o en el surco de siembra, puede constituirse en una excelente opción para el control de fitopatógenos que habitan el suelo (Lewis \& Papavizas, 1991).

Entre las bacterias utilizadas para el biocontrol de fitopatógenos que habitan el suelo, se destacan las bacterias fluorescentes del género Pseudomonas, que son metabolicamente más activas. con alta tasa de crecimiento y predominan en la rizósfera (Lemanceau, 1992). Los principales mecanismos de biocontrol que presenta este grupo de bacterias incluyen: competición de micronutrientes debido a la exudación de las semillas o raíces, bloqueo de sitios de penetración, producción de sideróforos, producción de antibióticos e inducción de resistencia (Défago \& Haas, 1991).

A pesar del énfasis dado a la investigación sobre el control biológico de $R$. solani con Pseudomonas spp. fluorescentes (Howell \& Stipanovic. 1979; Gells \& Schippers, 1983; Mew \& Rosales. 1986; Barbosal ct al, 1995), pocos agentes eficaces están disponibles (Powell et al., 1990) además de otros motivos. debido a la variabilidad de su desempeño en condiciones diferentes (Kloepper, 1991).

Este estudio tuvo como objetivo investigar el efecto del tratamiento de semillas de algodón con Pseudomonas $s p p$. fluorescentes para el control de $R$. solani en plántulas.

\section{MATERIALES Y METODOS}

1.- Candidatos antagónicos. Se utilizaron cepas de Pseudomonas spp. fluorescentes de la Colección de Cultivos de Microorganismos del Laboratorio de Fitobacteriologia (Departamento de Agronomia, Universidad Federal Rural de Pernambuco, Recife), obtenidas originalmente del rizoplano de varios cultivos vegetales.

2.- Fitopatógenos. Fueron utilizadas tres cepas de $R$. solani, pertenecientes al grupo de anastomosis 4 (AG-4), provenientes de plantas de algodón (RS-4), Vigna sp. (RS5) y frijol (RS-6) con sintomas de cancro en el hipocótilo y caída de plántulas, procedentes de áreas de sembradíos comerciales del Estado de Pernambuco.

La preparación de las suspensiones bacterianas y del inóculo del fitopatógeno, así como el tratamiento de las semillas de las plántulas, siguieron procedimientos previamente descritos (Barbosa et al, 1995). Las suspensiones de células de Pseudomonas spp. fluorescentes fueron preparadas en solución de $\mathrm{MgSO}_{4} 0,1 \mathrm{M}$ y ajustadas para aproximadamente $1 \times 10^{8}$ células $/ \mathrm{ml}$. El inóculo de $R$. solani fue preparado en sustrato constituido de arroz sin cáscara, autoclavado y pesado en alicuotas conforme a la concentración que se incorporaría en el suelo. Las semillas de algodón de la variedad Precoce-1, fueron desinfectadas con solución de $\mathrm{NaClO}$ 1,5\%, lavadas con agua destilada estéril y luego secadas, posteriormente fueron tratadas con las suspensiones bacterianas. El tratamiento considerado como testigo consistió en sumergir las semillas solamente en solución de $\mathrm{MgSO}_{4}$, sin las Pseudomonas $s p p$. fluorescentes. La siembra se efectuó en suelo no esterilizado e infectado artificialmente con $R$. solani.

3.- Selección preliminar de cepas de Pseudomonas spp. fluorescentes con potencial de biocontrol sobre $R$. solani en algodón. Se evaluaron 67 cepas de Pseudomonas spp. fluorescentes. Las semillas fueron tratadas con suspensiones bacterianas y sembradas en bandejas plásticas ( $30 \times 23 \times 4 \mathrm{~cm}$ y capacidad de $2 \mathrm{~kg}$ ), las cuales contenian suelo $(\mathrm{pH} 7,1$; materia orgánica. 3,$7 ; \mathrm{N} 1.442$ $\mathrm{ppm} ; \mathrm{P}>36 \mathrm{ppm} ; \mathrm{K}>250 \mathrm{ppm} ; \mathrm{Al} 0.05 \mathrm{meq} / 100 \mathrm{~cm}^{3} ; \mathrm{Ca}$ $7,90 \mathrm{meq} / 100 \mathrm{~cm}^{3}: \mathrm{Mg} 1.25 \mathrm{meq} / 100 \mathrm{~cm}^{3}$ ) previamente infectado con el sustrato colonizado por $R$. solani (cepa RS-4). en concentración de $50 \mathrm{mg} / \mathrm{kg}$ de suelo. El diseño experimental fue completamente al azar, con cinco repeticiones, donde cada repetición consistia en una bandeja con 25 scmillas.

La evaluación de la intensidad de la enfermedad se realizó a los 10 dias después de la siembra, utilizándose una escala de valores que varían de 0 a 4 , donde: $0=\sin$ síntomas: 1 = hipocótilo con pequeñas lesiones; $2=$ hipocótilo con grandes lesiones constreñidas; 3 = hipocótilo 
totalmente constreñido y caída $; 4=$ semillas sin germinar y/o plantas sin emerger. Con los datos obtenidos, se calculó el índice de intensidad de la enfermedad según Mckinney (1923) y a partir de éste, se calculó el índice de reducción de la intesidad de la enfermedad, mediante la fórmula adaptada de Edginton et al. (1971).

4.Eficacia de las cepas de Pseudomonas spp fluorescentes sobre diferentes cepas de Rhizoctonia solani. Para evaluar la eficacia frente a diferentes cepas de $\boldsymbol{R}$. solani, se utilizaron cinco cepas de Pseudomonas spp. fluorescentes (CB-33, CB-38, CR-7, P-5, P-8), las que preliminarmente presentaron un mayor potencial como agentes de biocontrol, además del fungicida Quintozene (Plantacol, 750 g.i.a./ kg), utilizado como patrón de control. Las semillas fueron tratadas con las suspensiones bacterianas o con el fungicida $(2.250 \mathrm{ppm})$ y sembradas en bandejas que contenían suelo previamente infectado por tres cepas de $\boldsymbol{R}$.solani (RS-4, RS-5 y RS-6), en concentración de $50 \mathrm{mg}$ de sustrato colonizado/kg de suelo. El diseño experimental utilizadofue completamente aleatorio, en arreglo factorial $3 \times 6$, con cinco repeticiones.

La evaluación se realizó conforme a lo descrito anteriormente.

\section{5.- Eficacia de cepas de Pseudomonas spp. fluorescentes,} bajo diferentes densidades de inóculo de $R$. solani.

Las cinco cepas de Pseudomonas spp. fluorescentes y el fungicida Quintozene, fueron evaluados bajo diferentes concentraciones de inóculo de $\boldsymbol{R}$. solani. Las semillas fueron tratadas con las suspensiones bacterianas o con el fungicida (2.250 ppm.) y sembradas en bandejas con suelo previamente infectado con sustrato colonizado por $\boldsymbol{R}$. solani (cepa RS-4) con densidades de 50,100 y $150 \mathrm{mg}$ / $\mathrm{kg}$ de suelo. El diseño experimental utilizado fue completamente aleatorio, en arreglo factorial $3 \times 6$, con cinco repeticiones. La evaluación se efectuó conforme lo descrito anteriormente.

Durante el período de ejecución de los experimentos, la temperatura en el invernadero fue de $31 \pm 3^{\circ} \mathrm{C}$ y la humedad relativa de $75 \pm 2 \%$.

\section{RESULTADOS Y DISCUSION}

Dentro de los 67 cepas de Pseudomonas spp. fluorescentes evaluadas como agentes de biocontrol de $\boldsymbol{R}$. solani en plantas de algodón, cinco (P-8, CR-27, CB-38, CB-33 E P-5) se destacaron como promisorias, al reducir la intensidad de la enfermedad a un $40 \%$ (Figura 1), las cuales fueron seleccionadas para próximas evaluaciones. Los resultados mostraron el potencial de las cepas de Pseudomonas spp. fluorescentes en la reducción de la caída de plantas de algodón ocasionadas por $\boldsymbol{R}$. solani, confirmando lo observado por Howell \& Stipanovic
(1979) y Hagedon et al. (1993). Las diferentes eficacias de las cepas de Pseudomonas spp. observadas durante el estudio mostraron su variabilidad, confirmando lo que evidenciaron Press \& Kloepper (1994) cuando notaron que la colonización de la raíz y el control de los patógenos en plantas hospedadoras, dependen de un grupo de parámetros.

La cepas de Pseudomonas spp. fluorescentes contra diferentes cepas de $\boldsymbol{R}$. solani, se mostraron siempre eficaces, controlando la caída de plantas de algodón sin diferencias entre sí (Tabla 1). Al considerar al conjunto de cepas del patógeno, y las antagónicas, las últimas se mostraron eficaces en el control de la enfermedad, sin diferir significativamente con el tratamiento con el fungicida Quintozene.

La cepa CB-33 y CR-27 se mostraron más eficaces al controlar la enfermedad, ocasionada por las cepas RS-4 y RS-6 del fitopatógeno respectivamente. Los tratamientos se mostraron más eficaces en la reducción de la intensidad de la enfermedad causada por la cepa RS-4 (algodón), que para las cepas RS-5 (Vigna sp.) y RS-6 (frijol). Según Broadbent et al. (1971), el alto grado de especificidad de la acción de un antagónico, puede ser obstáculo para el uso práctico del control biológico contra los hongos promotores de la caída de plantas, principalmente $\boldsymbol{R}$. solani en condiciones de campo.

Generalmente las cepas RS-5 y RS-6 de $\boldsymbol{R}$. solani, propiciaron mayor intensidad de la enfermedad, sin embargo no difirieron significativamente de la cepa RS-4. Estas variaciones, conforme a lo reportado por Ogoshi (1987), frecuentemente están relacionadas a la alta variabilidad genética, fisiológica y patogénica de $R$. solani.

Las cepas de Pseudomonas spp. fluorescentes, aplicadas a diferentes densidades del inóculo de $R$. solani, evidenciaron la eficacia en el control de la caida de las plantas de algodón (Tabla 2), aunque sin diferir significativamente al ejercido por el fungicida Quintozene. La reducción de la eficacia de los agentes biocontroladores fue proporcional al incremento de la densidad del inóculo del fitopatógeno. Resultados similares fueron obtenidos por Homma et al. (1991), al utilizar la cepa RB245 de $\boldsymbol{P}$. cepacia, en el control de $\boldsymbol{R}$. solani en remolacha. Entre las cepas de Pseudomonas spp. fluorescentes, se destacó la CB-33, como más eficaz en la densidad de inóculo de 50 $\mathrm{mg} / \mathrm{kg}$. de suelo, mientras que P-5 se destacó en densidades de 100 y $150 \mathrm{mg} / \mathrm{kg}$. de suelo.

El aumento de intensidad de la enfermedad fue proporcional al incremento de la densidad del inóculo del fitopatógeno, semejante a lo constatado porPhillips (1989), al evaluar varios cepas y densidades de $\boldsymbol{R}$. solani en plantas de frijol.

Los índices medios de intensidad de la enfermedad, observados en experimentos, indican la gran virulencia y agresividad del patógeno, altamente adaptado a las 
Tabla 1.- Eficacia de Is cepas de Pseudomonas spp. para el control de la caida de plantas de algodón causado por diferentes cepas de Rhizoctonia solani.

\begin{tabular}{|c|c|c|c|c|}
\hline \multirow[t]{2}{*}{ Tratamiento } & \multicolumn{3}{|c|}{ Cepas de Rhizoctonia solani } & \multirow[t]{2}{*}{ Media } \\
\hline & RS-4 & RS-5 & RS-6 & \\
\hline Testigo & $79,0^{1} \mathrm{aA}$ & 81,9 aA & $81,7 \mathrm{aA}$ & $80,9^{2} \mathrm{a}$ \\
\hline Quintozene & $47,4 \mathrm{bB}$ & $65,5 \mathrm{aA}$ & $61,7 \mathrm{abAB}$ & $58,1 \mathrm{~b}$ \\
\hline$P-5$ & $40,9 \mathrm{bB}$ & 72,4 aA & $59,8 \mathrm{abA}$ & $57,7 \mathrm{~b}$ \\
\hline P-8 & $46,9 \mathrm{bB}$ & 68,1 aA & $57,6 \mathrm{aAB}$ & $57,5 \mathrm{~b}$ \\
\hline $\mathrm{CB}-38$ & $41,7 \mathrm{bB}$ & 59,8 aA & $64,8 \mathrm{abA}$ & $55,4 \mathrm{~b}$ \\
\hline CB-33 & $34,3 \mathrm{bB}$ & $63,2 \mathrm{aA}$ & $60,9 \mathrm{abA}$ & $52,8 \mathrm{~b}$ \\
\hline CR-27 & $46,2 \mathrm{bAB}$ & $63,8 \mathrm{aA}$ & $43,8 \mathrm{bB}$ & $51,3 \mathrm{~b}$ \\
\hline Media & $48,1^{3} \mathrm{~B}$ & $67,8 \mathrm{~A}$ & $61,5 \mathrm{~A}$ & - \\
\hline
\end{tabular}

'Intensidad de la enfermedad, calculada de acuerdo a Mckinney (1923). Media de 4 repeticiones: ${ }^{2}$ Media de 12 repeticiones; ${ }^{3}$ Media de 28 repeticiones. Medias seguidas de la misma letra minúscula y mayúscula, no difieren estadisticamente entre si, con la prueba de Tukey (5\%).

Tabla 2. Eficacia de las cepas de Pseudomonas spp. para el control de la caída de plantas de algodón bajo diferentes densidades de inóculo de Rhizoctonia solani.( Cepa RS-4)

Tratamiento Densidad de Inoculo de Rhizoctonia solani ( $\mathrm{mg} / \mathrm{kg}$ )

Media

\begin{tabular}{lcccc}
\hline & 50 & 100 & 150 & \\
\hline Testigo & $77,9^{1} \mathrm{aB}$ & $86,0 \mathrm{aA}$ & $91,9 \mathrm{aA}$ & $85,2^{2} \mathrm{a}$ \\
Quintozene & $59,0 \mathrm{bB}$ & $73,1 \mathrm{bA}$ & $80,5 \mathrm{bA}$ & $70,9 \mathrm{~b}$ \\
CB-38 & $60,7 \mathrm{bC}$ & $71,2 \mathrm{bB}$ & $79,3 \mathrm{bA}$ & $70,4 \mathrm{~b}$ \\
CB-33 & $52,9 \mathrm{bC}$ & $72,1 \mathrm{bB}$ & $82,9 \mathrm{abA}$ & $69,3 \mathrm{~b}$ \\
CR-27 & $57,4 \mathrm{bC}$ & $69,9 \mathrm{bB}$ & $79,3 \mathrm{bA}$ & $68,9 \mathrm{~b}$ \\
P-8 & $57,6 \mathrm{bB}$ & $71,0 \mathrm{bA}$ & $77,6 \mathrm{bA}$ & $68,7 \mathrm{~b}$ \\
P-5 & $57,6 \mathrm{bC}$ & $65,7 \mathrm{bB}$ & $76,4 \mathrm{bA}$ & $66,6 \mathrm{~b}$ \\
\hline Media & $60,4^{3} \mathrm{~B}$ & $72,7 \mathrm{~B}$ & $81,1 \mathrm{~A}$ & - \\
\hline
\end{tabular}

${ }^{1}$ Intensidad de enfermedad, calculada de acuerdo a Mckinney (1923). Media de 4 repeticiones; ${ }^{2}$ Media de 12 repeticiones; ${ }^{3}$ Media de 28 repeticiones. Medias seguidas de la misma letra minúscula y mayúscula, no difieren estadisticamente entre sí, con la prueba de Tukey ( $5 \%$ ). 
condiciones ambientales del suelo y de la planta hospedadora (Papavizas, 1970).

Los posibles mecanismos de antagonismo envueltos en el control de $\boldsymbol{R}$. solani por cepas de Pseudomonas spp. fluorescentes verificados en este estudio, permanecen sin esclarecimiento. Según Andrews (1992), probablemente pocos microorganismos ejercen un único mecanismo de biocontrol, una vez que su importancia relativa puede variar conforme a las condiciones ambientales y al estado de desarrollo del agente biocontrolador y del antagónico.

Los resultados alcanzados muestran el potencial de algunas cepas de Pseudomonas spp. fluorescentes, como agentes de biocontrol de $\boldsymbol{R}$. solani en plantas de algodón, sin embargo hacen falta estudios complementarios en condiciones de campo.

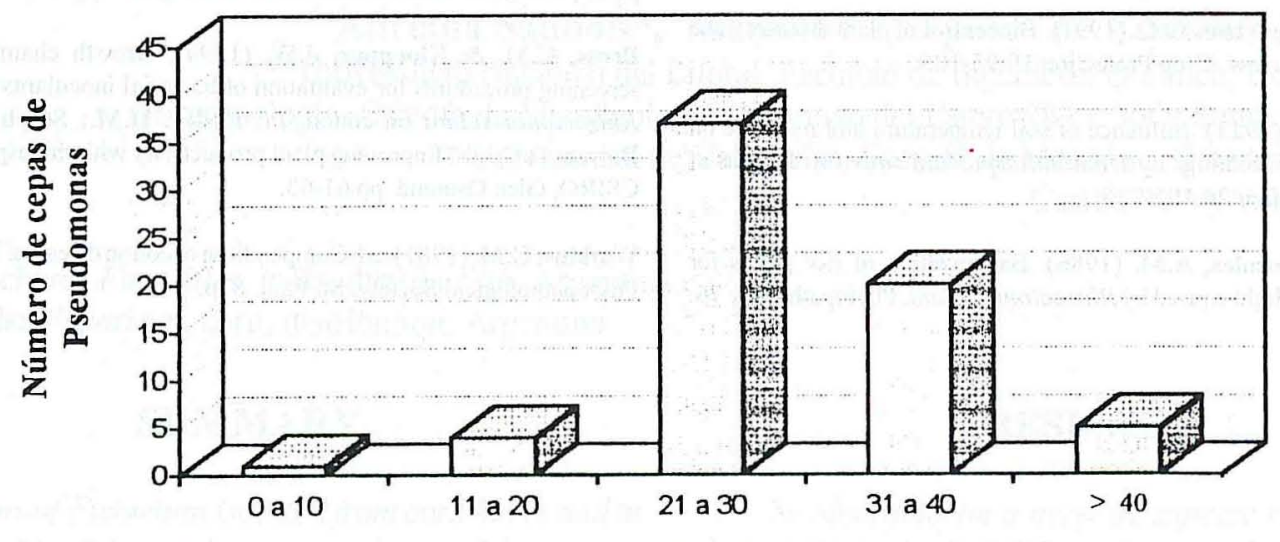

Reducción de Intensidad de la Enfermedad (\%)

Figura 1. Selección de cepas de Pseudomonas spp. fluorescentes con potencial de biocontrol sobre Rhizoctonia solani en plántulas de algodón.

\section{REFERENCIAS}

Andrews, J.HI. (1992). Biological control in the phyllosphere. Annual Review of Phytopathology 30:603-635

Barbosa, M.A.G.; Micheref,, S.J.; Mariano, R.L.R. \& Maranhão, F. (1995). Biocontrole de Rhizoctonia solani em caupi pelo tratamento de sementes com Pseudomonas spp. fluorescentes. Summa Phytopathologica 21:151-157

Broadbent, P.; Baker, K.F. \& Waternorye, Y. (1971). Bacteria and actinomycetes antagonistic to fungal root pathogens in Australian soils. Australian Journal of Biological Science 24:925-944

Cia, E. (1977). Ocorrência e conhecimento das doenças de algedoeiro anual Gossypium hirsutum L. no Brasil. Summa Phytopatholugica 3:167193

C.ook, R.J. \& Baker, K.F. (1983). Nature and practice of biological control of plant pathogens. The American Phytopathological Society, St. Paul.
Défago, (. \& Ilaas, D. (1991). Pseudomonads as antagonists of soilborne plant pathogens: Mode of action and genetic analysis. In: Bolag, J.; Stotzky, G. eds. Soil biochemistry. Marcel Dekker, New York. pp.249291

Edginton, I_V.; Khew, K.I_ \& Marron, G.I_ (1971). Fungitoxic espectrum of benzimidazole compounds. Phytopathology 61:42-44

(iecls, F.P. \& Schippers, B. (1983). Reduction of yield depressions in high frequency potato cropping soil after seed tuber treatments with antagonistic fluorescent P'seudomonas spp. Phytopathologishe Zeitschrift 108: 207 214

Hagedorn, C.; Gould, W.D. \& Bardinelli, T.R.(1993). Field evaluations of bacterial inoculants to control seedling disease pathogens on cotton. Plant Disease 77:278-282

Homma, Y.; Chikuo, Y. \& Ogoshi, A. (1991). Mode of supression of sugar beet damping-off caused by Rhizoctonia solani by seed bacterization with Pseudomonas cepacia. WPRS Bulletin. 14:115-118 
Howell, C.R. \& Stipanovic, R.D. (1979). Control of Rhizoctonia solani on cotton seedling with Pseudomonas fluorescens and with an antibiotic produced by the bacterium. Phytopathology 69: 480-482

Kloepper, J.W.(1991). Development of "in vivo" assays for prescreening antagonists of Rhizoctonia solani on cotton. Phytopathology 81:10061013

Leach, L.D. \& Garber, R.H. (1970). Control of Rhizoctonia. In: Parmeter, J.R. ed. Rhizoctonia solani: biology and pathology. The University of California Press, Berkeley. pp.189-199.

Lemanceau, P. (1992). Effets benéfiques de rizobactéries sur les plantes: Exemple des Pseudomonas spp. fluorescents. Agronomie 12:413-437

Lewis, J.A. \& Papavizas, G.C. (1991). Biocontrol of plant diseases: The approach for tomorrow. Crop Protection 10:95-105

Mckinney, R.H. (1923). Influence of soil temperature and moisture on infection of wheat seedlings by Helminthosporium sativum. Journal of Agricultural Research 26:195-218

Mew, T.W. \& Rosales, A.M. (1986). Bacterization of rice plants for control of sheath blight caused by Rhizoctonia solani. Phytopathology 76: $1260-1264$
Ogoshi, A. (1987). Ecology and pathogenicity of anastomosis and intraspecific groups of Rhizoctonia solani Kühn. Annual Review of Phytopathology 15:125-143

Papavizas, G.C. (1970). Colonization and growth of Rhizoctonia solani in soil. In: Parmeter, J.R. ed. Rhizoctonia solani: biology and pathology. The University of California Press, Berkeley. pp.108-124.

Phillips, A.J.L. (1989). Relationship of Rhizoctonia solani inoculum density to incidence of hypocotyl rot an damping-off in dry beans. Canadian Journal of Microbiology 35:1 132-1140

Powell, K.A.; Faull, J.C. \& Renwick, A. (1990). The commercial and regulatory challenge. In: Hornby, D. ed. Biological control of soil-borne plant pathogens. $\mathrm{CAB}$ International: Wallingford. pp.445-464.

Press, C.M. \& Kloepper, J.W. (1994). Growth chamber and field screening procedures for evaluation of bacterial inoculants for control of Rhizoctonia solani on cotton. In: Ryder, H.M.; Stephens, M.P. \& Bowen, D.G. eds. Improving plant productivity with rhizosphere bacteria. CSIRO, Glen Osmond. pp.61-63.

Watkins, G.M.(1981). ed.Compendium of cotton diseases. The American Phytopathological Society, St. Paul. 87p. 